\title{
Case Report \\ Primary Cutaneous CD30-Positive Large T-Cell Lymphoma in an 80-Year-Old Man: A Case Report
}

\author{
Rehan Hussain ${ }^{1}$ and Amir Bajoghli', 2 \\ ${ }^{1}$ School of Medicine, The George Washington University, Washington, DC 20037, USA \\ ${ }^{2}$ Skin and Laser Surgery Center, Center for Mohs \& Skin Cancer Surgery, 8130 Boone Boulevard No. 340, Vienna, VA 22182, USA
}

Correspondence should be addressed to Rehan Hussain, rhussain27@gmail.com

Received 19 January 2011; Accepted 15 February 2011

Academic Editor: J. C. Szepietowski

Copyright (c) 2011 R. Hussain and A. Bajoghli. This is an open access article distributed under the Creative Commons Attribution License, which permits unrestricted use, distribution, and reproduction in any medium, provided the original work is properly cited.

\begin{abstract}
Primary cutaneous CD30-positive large cell lymphoma (CD30+ PCLCL) is a rare subtype of cutaneous T-cell lymphoma (CTCL) that can present in a variety of ways. We report a patient with a three-month history of an enlarging, exophytic mass with two smaller satellite lesions on the left forearm. Biopsy of the skin stained positive for CD30, and, after thorough systemic evaluation, a diagnosis of CD30+ PCLCL was made. When PCLCL is suspected, it is important to perform immunohistological studies for CD30 types and conduct a thorough workup to rule out systemic LCL. These measures will reduce the use of unnecessarily aggressive chemotherapy regimens for CD30+ PCLCL, an indolent disease with a favorable prognosis.
\end{abstract}

\section{Introduction}

CD30+ PCLCL represents about ten percent of all cases of cutaneous T-cell lymphomas [1], and it is thought to represent a spectrum of disease, with lymphomatoid papulosis at the benign end, and primary cutaneous anaplastic large cell lymphoma (PCALCL) at the other $[2,3]$. CD30positive large cell lymphomas are typically associated with poor prognosis when they are systemic, though they have a favorable prognosis when confined to the skin. CD30 expression is a much more important prognostic parameter than is the extent of skin disease at presentation, as Beljaards et al. [4] described that $80 \%$ of patients with CD30-negative PCLCL died of progressive disease (median 27 months after diagnosis) compared to only $7 \%$ of patients with $\mathrm{CD} 30+$ PCLCL.

\section{Case Presentation}

An 80-year-old male was seen with a three-month history of a mass on the left inner forearm that was getting persistently larger and bleeding. Physical examination showed the presence of a $10.0 \times 7.0 \mathrm{~cm}$ exophytic nodule on the left wrist and forearm. Two smaller satellite nodules were seen along the mid dorsal forearm, each measuring $2.0 \times$ $2.0 \mathrm{~cm}$ (Figure 1). No adenopathy was noted. CBC and other laboratory values were unremarkable. A bone marrow biopsy was performed, and the results were normal. PET scan, CT scan of the chest and abdomen, and chest X-ray were all normal. A biopsy was taken at the time. It showed a polypoid lesion characterized by a dense perivascular and band-like monomorphous infiltrate composed of markedly atypical, large, pleomorphic epithelioid cells, as well as immature cells resembling immunoblasts (Figures 2 and 3). Mitoses and tumor necrosis with accompanying neutrophils were noted. Reed-Sternberg cells, however, were not observed. Over 75\% of the atypical lymphoid cells expressed CD30 (Figure 4), but not ALK1 (Figure 5) and EMA (Figure 6), which led to the diagnosis of $\mathrm{CD} 30+$ primary cutaneous anaplastic large cell lymphoma (CD30+ PCLCL). The patient received localized radiation treatment with excellent results, as the tumor has completely remitted.

\section{Discussion}

CD30+ PCLCL usually presents in adults, age 45-60, and is six-times more frequent in males [5]. It presents as 


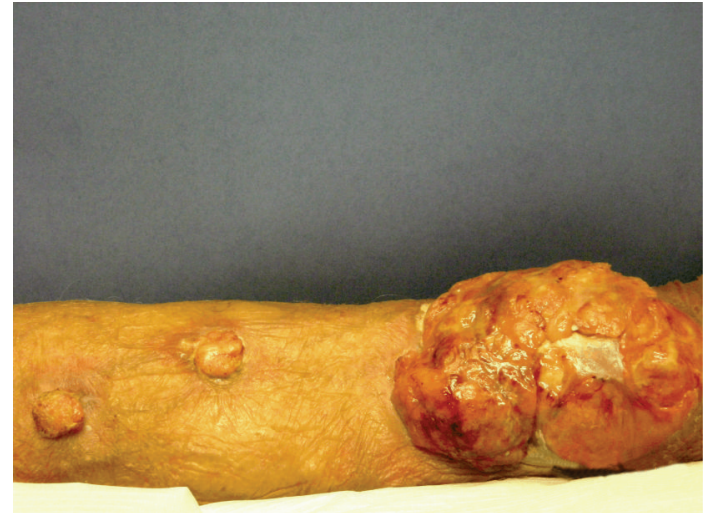

Figure 1: Patient's left forearm with large exophytic tumor and two satellite tumors.

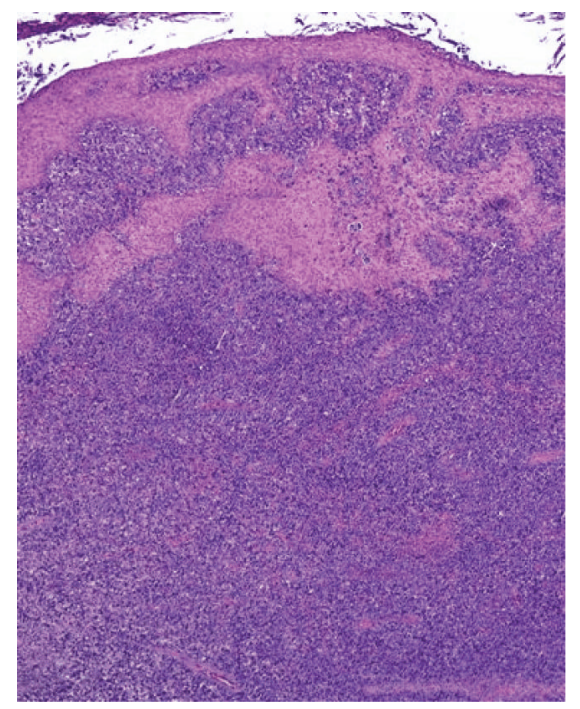

Figure 2: H\&E staining of the tumor shows a dense perivascular and band-like monomorphous infiltrate composed of markedly atypical, large, pleomorphic epithelioid cells, along with immature cells resembling immunoblasts.

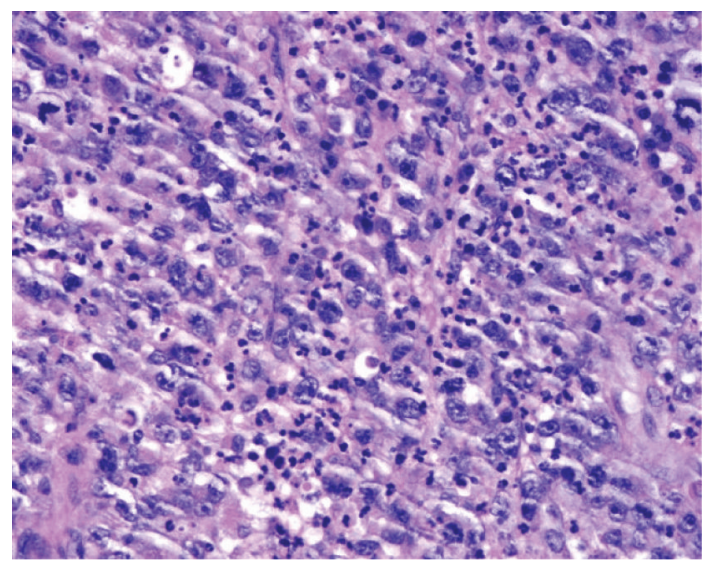

FIGURE 3: H\&E staining of the tumor shows a dense perivascular and band-like monomorphous infiltrate composed of markedly atypical, large, pleomorphic epithelioid cells, along with immature cells resembling immunoblasts.

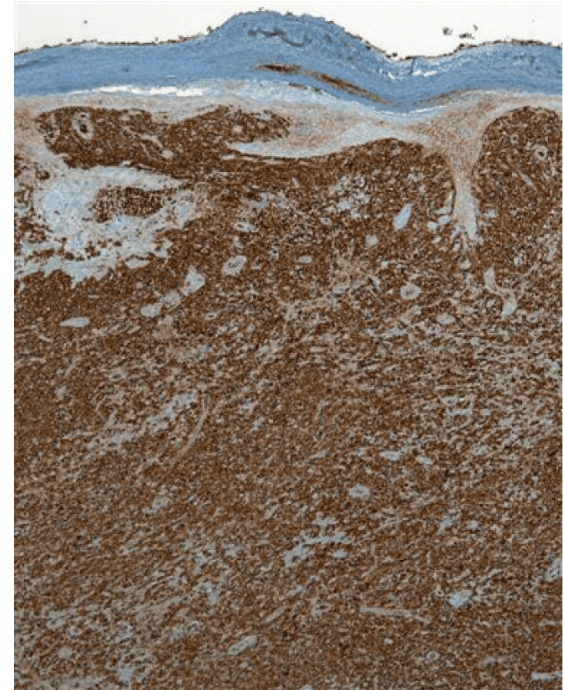

FIgUre 4: Histological image of the tumor stained to show expression of the CD30 surface marker on the atypical lymphoid cells.

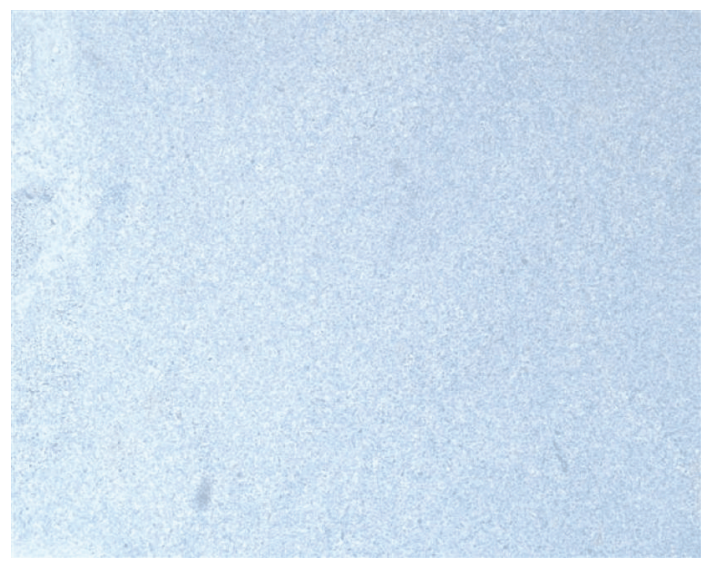

FIGURE 5: Histological image of the tumor that shows absence of the ALK-1 protein on the atypical lymphoid cells.

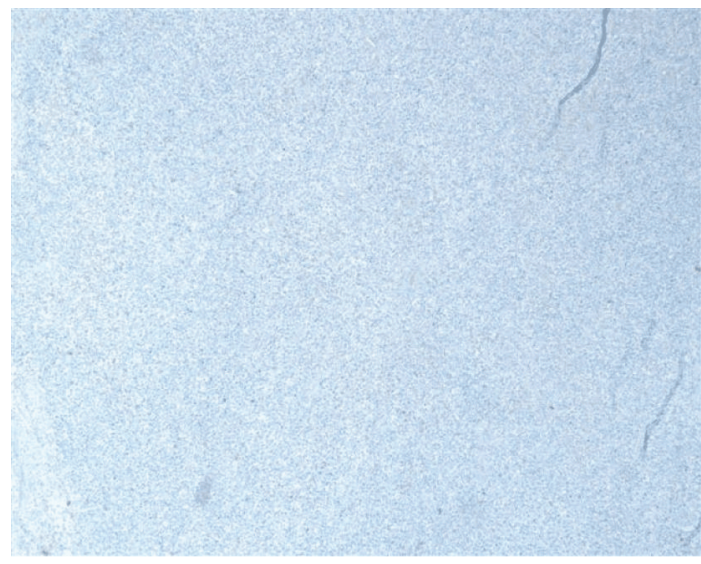

FIGURE 6: Histological image of the tumor that shows absence of the EMA surface marker on the atypical lymphoid cells. 
one to several localized nodules or tumors with ulceration. Twenty percent of cases are multifocal, and the trunk and extremities are most commonly involved. Plaques are greater than $1 \mathrm{~cm}$ in most cases (77\%). Draining lymph nodes are a positive finding in about $25 \%$ of cases. Additional common features are epidermal ulceration $(63 \%)$, prominent vascular proliferation (60\%), pseudoepitheliomatous hyperplasia (55\%), tumor necrosis (55\%), and vascular infiltration by neoplastic cells (44\%) [5]. In 20-25\% of cases, Reed-Sternberg-like pleomorphic or immunoblastic cells are present [6]. Presentation may be variable, with this lesion being mistaken for other skin disorders, such as adultonset eczema, pyoderma gangrenosum, morphea, localized scleroderma, or squamous cell carcinoma [7].

Histopathologically, dense clusters or nodules of large CD30+ tumor cells are observed in PCALCL; more than 75 percent of tumor cells should be CD30+ for a diagnosis of PCALCL. The CD30+ tumor cells are CD4+, and can have loss of T-cell markers, such as CD2, CD3, and CD5. Cell surface markers can help in distinguishing PCALCL from its primary nodal counterpart with secondary cutaneous disease. The PCALCL tumors more commonly express HECA-452 and not EMA whereas secondary disease is more likely to express EMA and not HECA-452 [1]. Systemic lymphomas are also more likely to contain the $t(2 ; 5)$ translocation, which creates the fusion protein NPM-ALK (nucleophosmin-anaplastic lymphoma kinase) $[8,9]$.

CD30+ anaplastic large cell lymphomas are typically associated with poor prognosis when they are systemic, though they have a favorable prognosis when confined to the skin [4]. The survival rate of CD30+ PCLCL is $95 \%$ at five years after diagnosis, and about $20 \%$ of lesions regress spontaneously [10]. However, CD30-negative PCLCL is a much more aggressive neoplasm (though it is indistinguishable from CD30+ PCLCL on gross examination), with a $15 \% 5$-year survival [4]. It is crucial to distinguish CD30+ PCLCL from primary nodal LCL with secondary cutaneous involvement, because patients with secondary skin disease generally have a worse prognosis and need to be treated more aggressively. The presence of draining lymph nodes does not seem to alter prognosis. There are no clinical differences in presentation, course, or prognosis between anaplastic and nonanaplastic CD30+ LCL [4].

The standard treatment of single or localized PCALCL lesions is either local excision or radiation. Chemotherapy is usually reserved for patients with systemic involvement. The treatment of patients with only skin and nodal disease is controversial, with some practitioners favoring radiation and chemotherapy for these patients [1].

\section{Conclusion}

Primary cutaneous CD30-positive large T-cell lymphoma may present in a variety of ways, but is definitively distinguished from other cutaneous T-cell lymphomas by the expression of the CD30 antigen on immunohistological staining. Other cell surface markers, such as EMA and ALK1 are helpful in distinguishing CD30+ PCLCL from secondary cutaneous CD30+ LCL, which influences the prognosis and decision to add chemotherapy to the treatment regimen.

\section{Consent}

Written informed consent was obtained from the patient for publication of this case report and any accompanying images. A copy of the written consent is available for review by the Editor-in-Chief of this journal.

\section{Conflict of Interests}

The authors declare that no financial or nonfinancial support was received, and that they have no competing interests.

\section{References}

[1] M. A. Fung, M. J. Murphy, D. M. Hoss, and J. M. GrantKels, "Practical evaluation and management of cutaneous lymphoma," Journal of the American Academy of Dermatology, vol. 46, no. 3, pp. 325-357, 2002.

[2] J. A. Stein, A. C. Soldano, and J. A. M. Latkowski, "Anaplastic large-cell T-cell lymphoma," Dermatology Online Journal, vol. 14, no. 5, Article ID 15, 2008.

[3] M. Paulli, E. Berti, R. Rosso et al., "CD30/Ki-1-positive lymphoproliferative disorders of the skin-clinicopathologic correlation and statistical analysis of 86 cases: a multicentric study from the European Organization for Research and Treatment of Cancer Cutaneous Lymphoma Project Group," Journal of Clinical Oncology, vol. 13, no. 6, pp. 1343-1354, 1995.

[4] R. C. Beljaards, P. Kaudewitz, E. Berti et al., "Primary cutaneous CD30-positive large cell lymphoma: definition of a new type of cutaneous lymphoma with a favorable prognosis: a European multicenter study of 47 patients," Cancer, vol. 71, no. 6, pp. 2097-2104, 1993.

[5] J. Krishnan, M. M. Tomaszewski, and G. F. Kao, "Primary cutaneous CD30-positive anaplastic large cell iymphoma. Report of 27 cases," Journal of Cutaneous Pathology, vol. 20, no. 3, pp. 193-202, 1993.

[6] R. Willemze and C. J. L. M. Meijer, "Primary cutaneous CD30positive lymphoproliferative disorders," Hematology/Oncology Clinics of North America, vol. 17, no. 6, pp. 1319-1332, 2003.

[7] C. Camisa, T. N. Helm, C. Sexton, and R. Tuthill, "Ki-1positive anaplastic large-cell lymphoma can mimic benign dermatoses," Journal of the American Academy of Dermatology, vol. 29, no. 5 I, pp. 696-700, 1993.

[8] K. A. Cataldo, S. M. Jalal, M. E. Law et al., "Detection of $\mathrm{t}(2 ; 5)$ in anaplastic large cell lymphoma: comparison of immunohistochemical studies, FISH, and RT-PCR in paraffinembedded tissue," American Journal of Surgical Pathology, vol. 23, no. 11, pp. 1386-1392, 1999.

[9] C. Querfeld, I. Khan, B. Mahon, B. P. Nelson, S. T. Rosen, and A. M. Evens, "Primary cutaneous and systemic anaplastic large cell lymphoma: clinicopathologic aspects and therapeutic options," Oncology, vol. 24, no. 7, pp. 574-587, 2010.

[10] M. W. Bekkenk, F. A. Geelen, P. C. Van Voorst Vader et al., "Primary and secondary cutaneous CD30-positive lymphoproliferative disorders: a report from the Dutch Cutaneous Lymphoma Group on the long-term follow-up data of 219 patients and guidelines for diagnosis and treatment," Blood, vol. 95, pp. 3653-3661, 2000. 


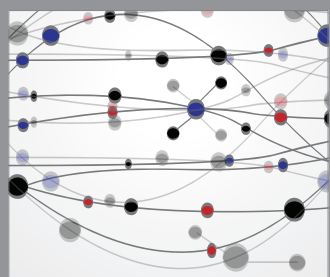

The Scientific World Journal
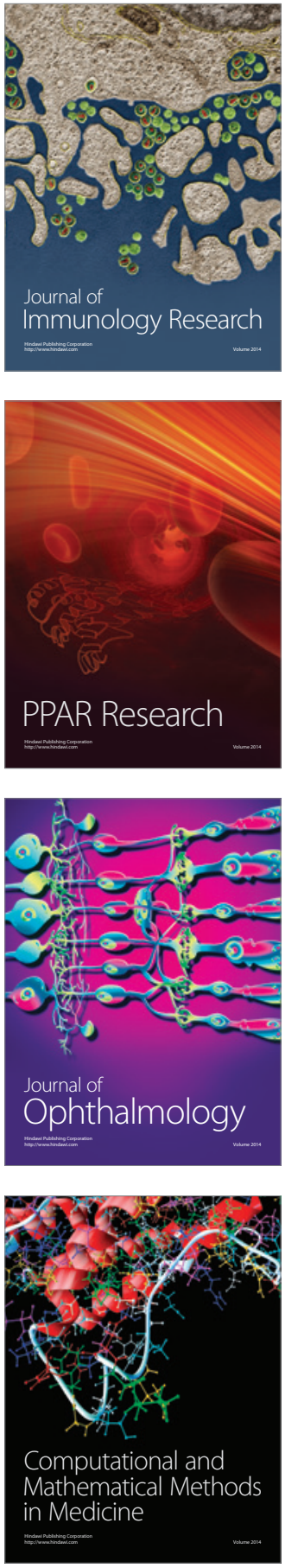

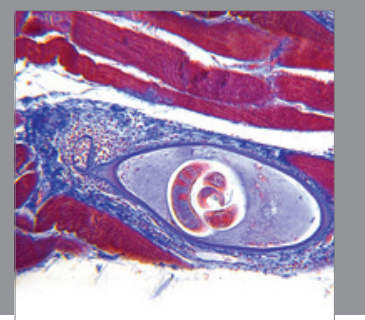

Gastroenterology

Research and Practice
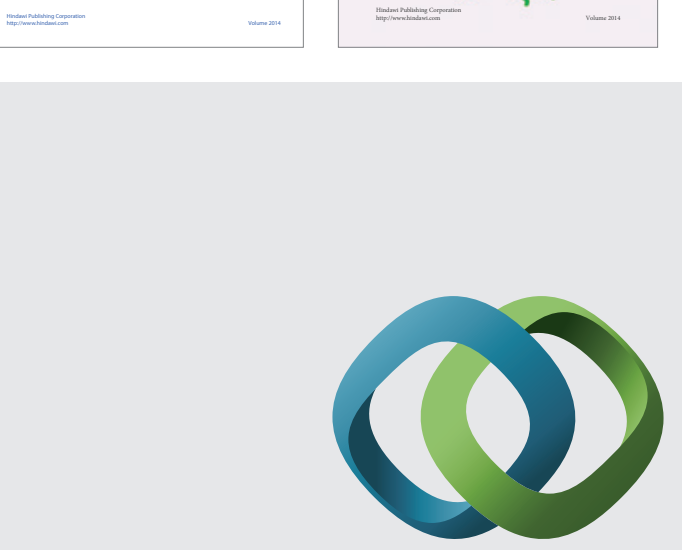

\section{Hindawi}

Submit your manuscripts at

http://www.hindawi.com
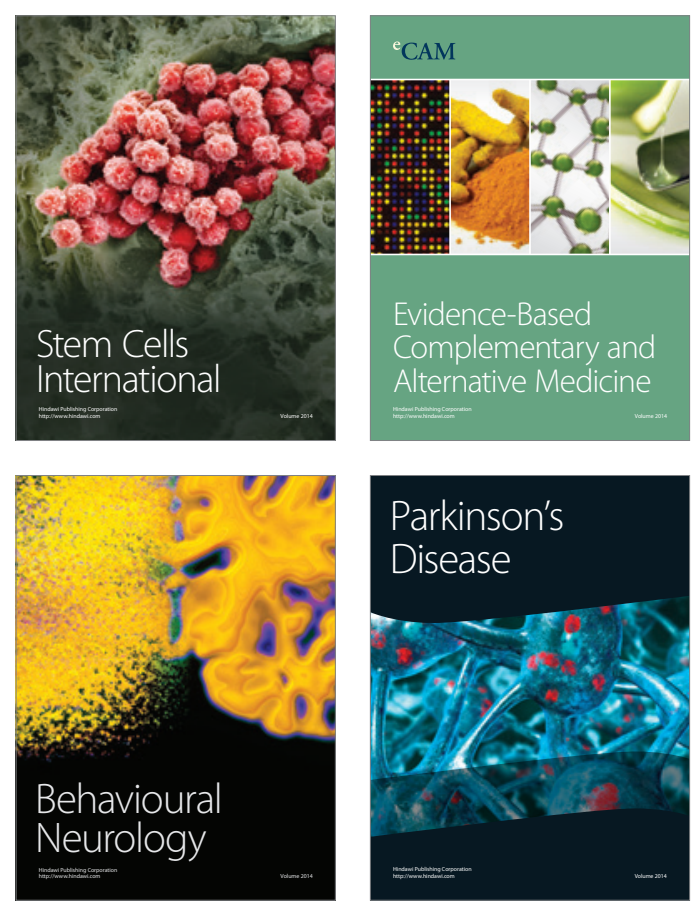

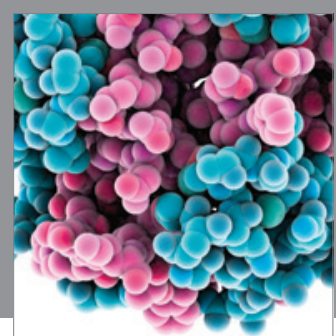

Journal of
Diabetes Research

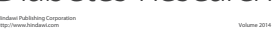

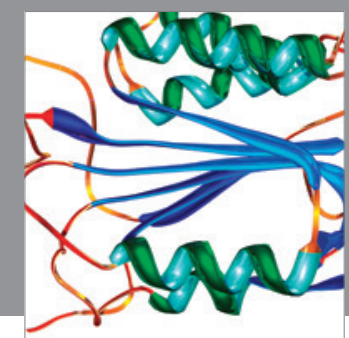

Disease Markers
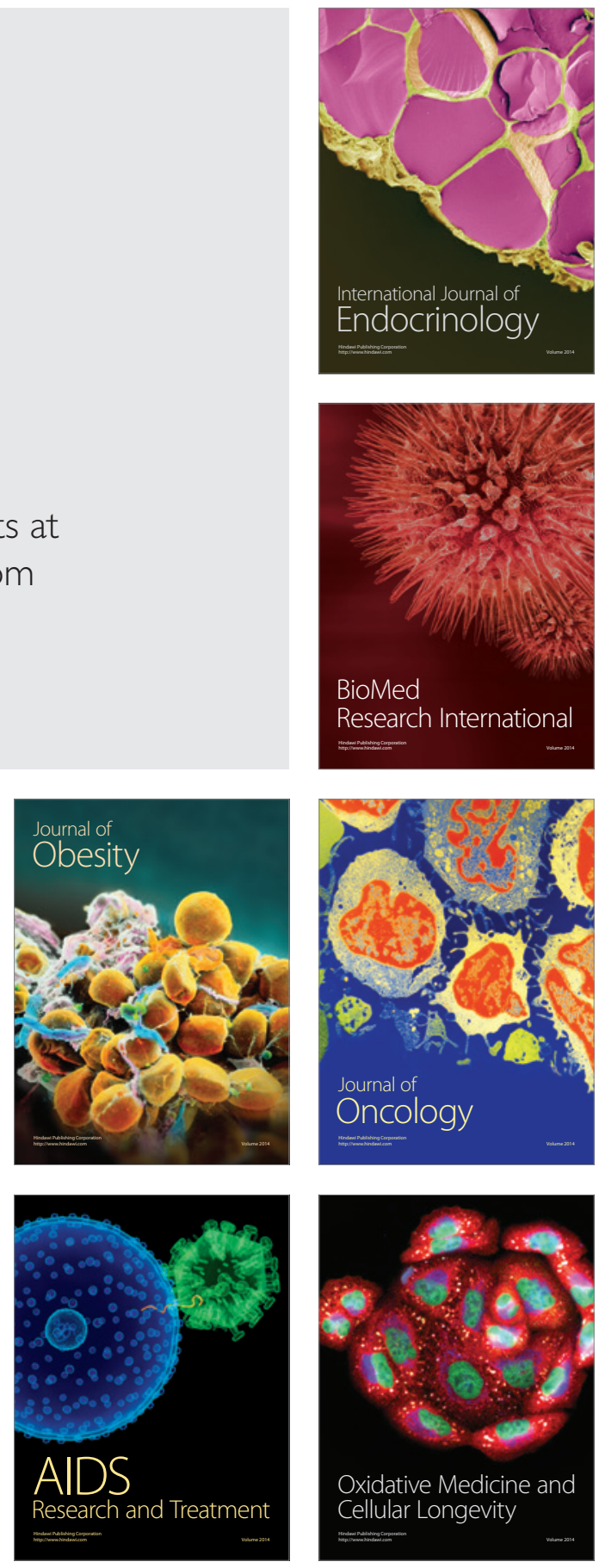